\title{
The Influence of Gonadectomy on Anxiolytic and Antidepressant Effects of Melatonin in Male and Female Wistar Rats: A Possible Implication of Sex Hormones
}

\author{
El Mrabet Fatima Zahra*, Lagbouri Ibtissam, Mesfioui Abdelhalim, El Hessni Aboubakr, \\ Ouichou Ali
}

Laboratory of Genetics, Neuroendocrinology and Biotechnology, Unit of Nervous and Endocrine Physiology, Department of Biology, Faculty of Sciences, University Ibn Tofail, Kenitra, Morocco.

Email: \{ ${ }^{*}$ fatimaa93, ouichou\}@hotmail.com

Received February 17 ${ }^{\text {th }}, 2012$; revised March 16 $6^{\text {th }}, 2012$; accepted April $5^{\text {th }}, 2012$

\begin{abstract}
The main objective of this study was to analyze the effects of sex, ovariectomy (Ovx) and orchidectomy (Orx) on antidepressant and anxiolytic effect of melatonin in forced swimming test, open field test and elevated plus maze test. Initially, $4 \mathrm{mg} / \mathrm{kg}$ of melatonin was daily administered, at $4: 00 \mathrm{pm}$, to intact male and female rats during 8 weeks. Our results have shown that the effect of chronic injection of Mel is sex dependent in the three behaviors tests. Females rats have responded better than males in behavior test study after administration of melatonin, this difference between the sexes may be related to the action of sex hormones (androgens and estrogens) on behavior in males as well as in females. Secondly, to determine the possible interaction between Melatonin and steroid hormones, Ovx/sham female received $\mathrm{Mel}$ at dose of $4 \mathrm{mg} / \mathrm{kg}$ alone or $\mathrm{NaCl}(0.9 \%)$ alone, and Orx $/ \mathrm{sham}$ male received Mel at dose of $4 \mathrm{mg} / \mathrm{kg}$ alone or $\mathrm{NaCl}(0.9 \%)$ alone daily and during 8 weeks of treatment at 4:00 pm. All animals were tested in the open-field test, elevated plus maze test for anxiety behavior study, and forced swimming test for depression behavior study. Results revealed that $\mathrm{Mel}$ exerts an anxiolytic and antidepressant effects in the orchidectomized males and in intact females, confirming that the suppression of androgens by orchidectomy improved anxiolytic and antidepressant effects of melatonin in males. However in females, the suppression of estrogen by ovariectomy masked the antidepressant and anxiolytic effects of melatonin. Our results confirmed that the antidepressant and anxiolytic effects of melatonin are linked to sex hormones.
\end{abstract}

Keywords: Melatonin; Sex Dependent; Anxiety; Depression; Behavior Tests; Ovariectomy; Orchidectomy; Sex Hormones

\section{Introduction}

In the rat, rhythmic melatonin production is driven by a circadian rhythm of the activity of pineal $N$-acetyltransferase (NAT) which synthesizes the melatonin precursor $\mathrm{N}$-acetylserotonin [1]. The NAT rhythm is controlled by a light-entrainable circadian pacemaking system in the suprachiasmatic nucleus (SCN) of the hypothalamus; SCN lesions abolish this rhythm [2]. Photic information is conveyed to the SCN by a direct retinal projection, the retinohypothalamic tract, and, to a lesser extent, also by other pathways especially by the geniculohypothalamic tract $[3,4]$. In the rat, these photic inputs terminate mostly in the ventrolateral (vl) or ventral part of the SCN $[4,5]$.

"Corresponding author.
The vl-SCN exhibits a rhythm of sensitivity to light [6]. Norepinephrine released at night from sympathetic nerve endings in the pineal gland stimulates adrenergic recaptors and the cAMP pathway; the resulting induction and activation of pineal NAT activity leads to high nighttime melatonin levels [7]. Once synthesized, melatonin is released directly into general circulation to establish its endocrine function on blood glucose, appetite, and sleep. In addition to these functions, melatonin seems to exert psychotropic effects in rodents, such as sedative activeties, analgesic, anticonvulsionants, anxiolytic and antidepressant $[7,8]$. In humans, melatonin has been studied for possible application in disorders of mood disturbances that were evident in the circadian profile of melatonin in depressed patients [9]. The anxiolytic effects of mela- 
Male and Female Wistar Rats: A Possible Implication of Sex Hormones

tonin have been frequently reported in experimental situations such as "the passive avoidance test", "open field test or high cross", which are constructed situations to induce a "state" of anxiety in the both sex of rats [10].

Thereafter, the Sex differences in the diagnosis of major depressive disorder in humans [11], and in the relative efficacy of various antidepressants [12], have frequently been reported; the results of pharmacological investigations have revealed differences between men and women. These apparent sex differences in response to antidepressants may be attributable to varying steroid levels. Estradiol can exert profound effects on mood by acting on neurotransmitter systems that are implicated in depression [11]. Sex differences in the immobility behavior have been reported in the forced swimming test (FST). Thus, intact male rats show higher levels of immobility $[14,15]$ and a reduced sensitivity to antidepressants $[15,16]$ compared to females. Thus, progesterone and different estrogenic compounds produce antidepressant-like effects in ovariectomized rats [17-20].

In fact, it has been proposed that lower nocturnal melatonin may be a trait-dependent marker for depression $[21,22]$. Pharmacological investigations have also supported the notion of an antidepressive potential for melatonin [21,22].

Knowing that the estrogen receptor and/or androgens are located on the same brain regions where melatonin receptors are dominant [23], it is mainly the limbic system, hippocampus, hypothalamus and amygdala, it has been suggested that the hormone, melatonin, possesses therapeutic benefits to individuals suffering from depression [23]. Although controlled, clinical trials have not been performed. However, few existing studies demonstrated that the effects of melatonin treatment on forcedswim test behaviors are sex-dependent [24], and a previous study have shown similar result, females treated with melatonin have respond better than men in anxiety and depression tests.

The main purpose of the current study was to investigate the influence of gonadectomy on antidepressant and anxiolytic effects of melatonin in male and female rats in forced-swim behavior, Elevated place maze, and open field test, in order to demonstrate an eventual implication of sexual hormones.

\section{Materials and Methods}

\subsection{Animals}

The Wistar rat is used for this study. The experiments were performed on male and female rat's initially weighing $(80 \pm 20) \mathrm{g}$. All rats were maintained on a $12 \mathrm{~h}$ Light $/ 12 \mathrm{~h}$ dark cycle and at a standard temperature $21 \mathrm{C}^{\circ}$ $\pm 1 \mathrm{C}^{\circ}$. Water and food were provided ad libitum. Female rats were bilaterally ovariectomized after being anesthetized with chloral hydrate $(0.5 \mathrm{ml} / 100 \mathrm{~g}$, sigmaaldrich, laborchemikalien Gmbh, Germany). In the ovariectomized rat $(\mathrm{Ovx})$ a ventral incision was made to expose the ovaries which were removed after ligation of the uterine horn. And male rats were orchidectomized (Orx). Briefly, a single midline incision was made in the scrotum and the testes exposed and removed. All rats were housed by sex in cages (6 rats/cage of $36 \mathrm{~cm}$ long, $20 \mathrm{~cm}$ wide and $15 \mathrm{~cm}$ high). At the beginning of treatment, the colony room was maintained under a long photoperiod LD: 16/8 (16 h Light/8h Darkness, lights off at $0000 \mathrm{~h}$ ).

\subsection{Experimental Procedure}

Melatonin (Sigma Lot No. 112K0998 France), was dissolved in 5\% ethanol. Seventy two rats received, at 4:00 pm during 8 weeks, daily subcutaneous injection of $\mathrm{NaCl}$ $(0.9 \%)$ or Melatonin at dose of $4 \mathrm{mg} / \mathrm{kg}$.

A first experimental series was designed to determine the antidepressant and anxiolytic effects of melatonin in intact male and female rats. Treated group (male and female 6 per cage per groups) received melatonin at dose of $4 \mathrm{mg} / \mathrm{kg}$. A control group received saline solution $\mathrm{NaCl}(0.9 \%)$ as vehicle.

The second experiments series was designed to determine the possible interaction between melatonin and steroid hormones in both sexes. Eight groups of rats $(\mathrm{Ovx} / \mathrm{sham}$ female received Mel at dose of $4 \mathrm{mg} / \mathrm{kg}$ alone or $\mathrm{NaCl}(0.9 \%)$ alone, and Orx/sham male received Mel at dose of $4 \mathrm{mg} / \mathrm{kg}$ alone or $\mathrm{NaCl}(0.9 \%)$ alone.

At the end of treatment, the rats were subjected to different behavioral tests to evaluate the anxiety and the depression levels. Open Field test (OFT), Elevated plus maze (EPM) and forced swimming test (FST) are undertaken in this order on 3 consecutive days without stopping treatment.

\subsection{Behavioral Testing}

\subsubsection{Open Field Test}

The investigatory behavior was tested in a wooden made apparatus $(100 \mathrm{~cm} \times 100 \mathrm{~cm})$. As previously reported [25], it was enclosed with $40 \mathrm{~cm}$ high walls and placed under strong illumination $(100 \mathrm{~W}, 2 \mathrm{~m}$ above the apparatus). The area was divided into 25 squares $(20 \mathrm{~cm} \times 20$ $\mathrm{cm})$, defined as 9 central and 16 peripheral squares. At the beginning of the 10-min test, the animal was placed in the center of the apparatus and its behavior was videotaped for subsequent analysis. The device was cleaned after each individual rat session. The quantified parameters were the time spent in the center of the area (TCA) and the number of returns to the nine square central sections (NRC). Central perimeter residence time is used as 
a measure of anxiety [26,27]. The number of returns to the central area is also an indicator of the emotional reactiveity [25]. The central area of a novel environment is anxiogenic and aversive and the behavioral inhibition appears therefore as an avoidance behavior towards the central zone of the open field [28]. The apparatus was cleaned between each examination using $70 \%$ ethyl alcohol.

\subsubsection{Elevated Plus-Maze Test}

The EPM is an ethological model of anxiety in rodents provoked by the novelty and repulsion as a result of elevation and illumination of the maze [29]. This test is based on the creation of a conflict between the exploratory drive of the rat and its innate fear of open and exposed areas; it has been validated for the detection of emotional responses to anxiogenic and anxiolytic substances [30]. Thus, increased open-arms exploration indicates reduced anxiety-related behavior. The EPM consists of a wooden plus-shaped platform elevated $70 \mathrm{~cm}$ above the floor. Two of the opposing arms $(50 \mathrm{~cm} \times 10$ $\mathrm{cm}$ ) are closed by $40 \mathrm{~cm}$ high side and end walls, having an open roof. In order to avoid fall, the other two arms (open arms) were surrounded by $0.5 \mathrm{~cm}$ high edge, the four arms had at their intersection a central platform (10 $\mathrm{cm} \times 10 \mathrm{~cm}$ ) [26]. A 100-W lamp was placed exactly over the central platform. At the beginning of the test, the rats were placed on the central area of the maze facing an open arm. The following parameters of anxiety-related behavior were measured during the 5 min testing period: 1) entries into open arms (EOA), 2) time spent on the open arms (TOA), 3) and number of full entries into the arms (TAE) [31]. Decreased anxiety-like behavior is illustrated by a significant statistical increase of parameters in open arms (time and/or entries). Although, entries in closed arms and total entries reflect the motor component of the exploratory activity [26,32]. To eliminate any lingering olfactory cues, the apparatus was cleaned between each examination using $70 \%$ ethyl alcohol.

\subsubsection{Forced Swimming Test}

The method followed was that described by [32]. Swimming sessions were conducted by placing the rat in individual glass cylinders (height $=50 \mathrm{~cm}$; diameter $=30 \mathrm{~cm}$ ) containing $30 \mathrm{~cm}$ of water at $\left(23^{\circ} \mathrm{C} \pm 2^{\circ} \mathrm{C}\right)$. During the session, rats were forced to swim for $5 \mathrm{~min}$ and the duration of immobility was measured. The latency to the first bout of immobility was also recorded starting immediately after placing the rats in the cylinder. A rat was judged immobile when it ceased all active behaviors (i.e. struggling, swimming and jumping) and remained passively floating or making minimal movements necessary to maintain the nostrils above water. High percent time floating is interpreted as an increased depressive-like response [32].

\subsection{Statistics}

All data are expressed as the means \pm standard error of the means (S.E.M.). To determine the differences between experimental groups statistical analysis was performed by analysis of variance (ANOVA) 1st/2nd order followed by a post-hoc tests (Fisher LSD) or Student test " $t$ ". Differences were considered significant when $p<$ 0.05 , very significant when $p<0.01$ and highly signifycant when $\mathrm{p}<0.001$.

\section{Results}

\subsection{Effect of Sex, While It Did Anxiolytic and Antidepressant Action of Melatonin in the Wistar Rat}

\subsubsection{Open Fieldtest}

\subsubsection{Time Spent in the Central Area (TCA) (Figure 1(a))}

The melatonin treatment showed highly significant effect $(p<0.001)$ and a sex effect was observed $(p<0.05)$. There was an interaction between melatonin and sex $(\mathrm{p}<$ 0.001). As well, females treated with melatonin spent highly significant time in center area compared with males treated with melatonin $\left(\mathrm{t}_{(3,16)}=9.13, \mathrm{p}=0.00001<\right.$ 0.001 ). The results of female groups revealed a signifycant difference between the control group and the treated one regarding the (TCA) parameter $\left(\mathrm{t}_{(3,16)}=7.73, \mathrm{p}=\right.$ $0.00005<0.001)$. Although, there were no significant difference between the two group in male rats $\left(\mathrm{t}_{(3,16)}=\right.$ $1.52, \mathrm{p}=0.16>0.05)$.

\subsubsection{Number of Returns to the Center (NRC)}

(Figure 1(b))

This parameter was significantly affected by melatonin treatment $(\mathrm{p}<0.01)$, and a sex effect $(\mathrm{p}<0.01))$ was observed. The interaction between melatonin and sex reached the statistical significance $(p<0.01)$. Melatonin treatment significantly increased the (NRC) in female rats than males $\left(\mathrm{t}_{(3,16)}=5.04, \mathrm{p}=0.0009<0.001\right)$. As compared to the control group, females treated with melatonin showed a significant difference in exploring the center of $(\mathrm{OF})\left(\mathrm{t}_{(3,16)}=4.16, \mathrm{p}=0.003<0.01\right)$, while this parameter did not differ significantly in males $\left(\mathrm{t}_{(3,16)}=\right.$ $-0.23, \mathrm{p}=0.82>0.05$ ).

\subsubsection{Locomotor Activity (NTS) (Figure 1(c))}

Locomotor activity was unaffected by melatonin treatment ( $p>0.05)$, and no effect of sex $(p>0.05)$ was noted. The interaction between melatonin and sex did not 


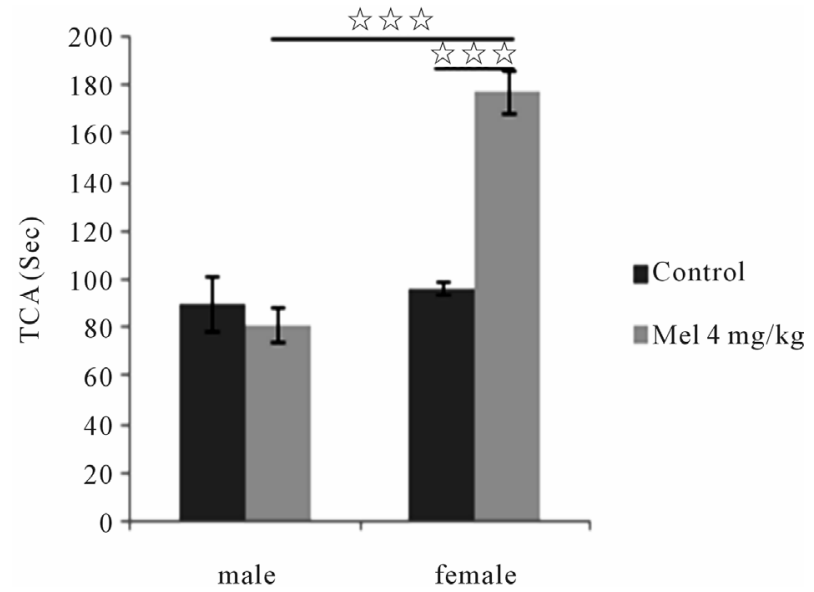

(a)

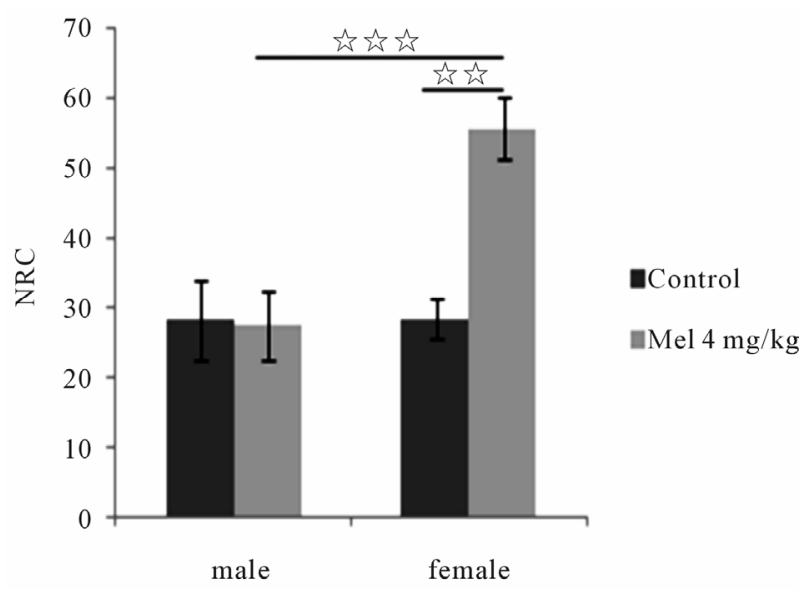

(b)

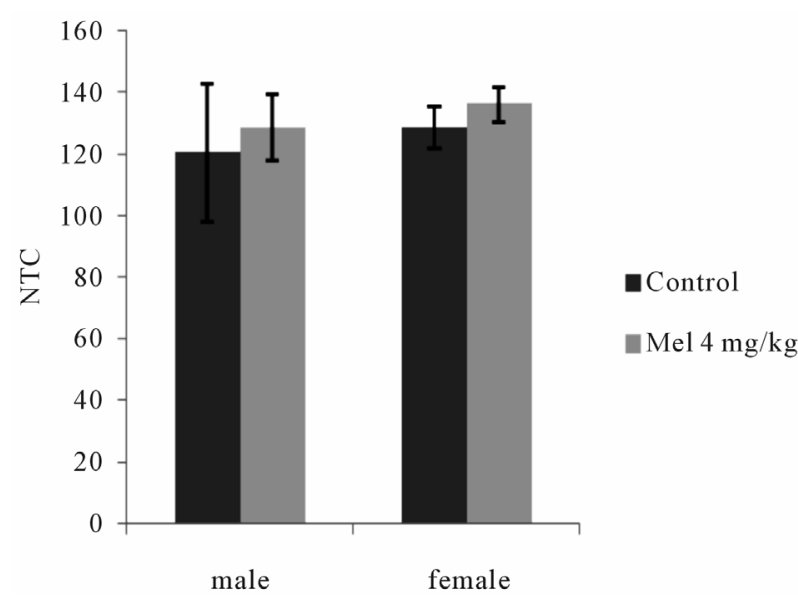

(c)

Figure 1. Mean (S.E.M.) (a) Total amount time spent in the center of the open field (TCA); (b) number of return into center area of the arena in the open-field behavior apparatus (NRC); and (c) the number of total squares (NTS); by female and male rats treated by $\mathrm{Mel}(4 \mathrm{mg} / \mathrm{kg})$ or $(\mathrm{NaCl}$ $0.9 \%$ ) beginning at 8 weeks of age and during 8 weeks of treatment. Values at distal ends of horizontal bar differ, ${ }^{*} p$ $<0.05,{ }^{* *}$ p $<0.01,{ }^{* * *}$ p $<0.001$. reach the statistical significance $(p>0.05)$. Also, in females, the group treated with melatonin no approached significance compared to the group control $\left(\mathrm{t}_{(3,16)}=1.93\right.$, $\mathrm{p}=0.08>0.05)$. The same result was observed in males $\left(\mathrm{t}_{(3,16)}=0.77, \mathrm{p}=0.46>0.05\right)$.

\subsubsection{Elevated Plus Maze}

\subsubsection{Entry to Open Arms (EOA) (Figure 2(a))}

The melatonin treatment significantly affected the open arm entries $(\mathrm{p}<0.01)$, and a sex effect was noted $(\mathrm{p}<$ $0.01)$. The interaction between melatonin and sex was observed $(p<0.001)$. Furthermore, statistical analyses revealed main effect of melatonin in females than males $\left(\mathrm{t}_{(3,16)}=3.44, \mathrm{p}=0.008<0.01\right)$. Significant difference between control and treated group was observed in females $\left(\mathrm{t}_{(3,16)}=2.33, \mathrm{p}=0.04<0.05\right)$. Whereas no statistical effect was found in males $\left(\mathrm{t}_{(3,16)}=-0.57, \mathrm{p}=0.58>\right.$ $0.05)$.

\subsubsection{Time Spent in Open Arms (TOA) (Figure 2(b))}

This parameter was affected by melatonin $(\mathrm{p}<0.001)$, and sex $(p<0.05)$. The interaction between the two factors reached a statistical significance $(p<0.001)$. In addition, females treated with melatonin spent highly significant time in the open arms than males treated with melatonin $\left(\mathrm{t}_{(3,16)}=6.16, \mathrm{p}=0.0002<0.001\right)$. As well, a significant difference was noted between the control and the treated female rats $\left(\mathrm{t}_{(3,16)}=4.12, \mathrm{p}=0.003<0.01\right)$. However, the melatonin failed to reach statistical significance in male $\left(\mathrm{t}_{(3,16)}=-0.09, \mathrm{p}=0.92>0.05\right)$.

\subsubsection{Total Entries in Arms (TEA) (Figure 2(c))}

Locomotor activity was unaffected by melatonin treatment $(p>0.05)$, and no main effect of sex $(p>0.05)$ was noted. There was no interaction between melatonin and $\operatorname{sex}(p>0.05)$. Also, melatonin didn't produced significant effect in both male $\left(\mathrm{t}_{(3,16)}=0.16, \mathrm{p}=0.86>0.05\right.$ and female $\left(\mathrm{t}_{(3,16)}=0.27, \mathrm{p}=0.79>0.05\right)$.

\subsubsection{Forced Swimming Test}

\section{Immobility Time (TIM) (Figure 3)}

The treatment of melatonin showed a significantly higher effect $(\mathrm{p}<0.001)$ on immobility time, and a sex effect ( $p$ $<0.05)$ was observed. Furthermore an interaction between melatonin and sex $(p<0.001)$ was noted. In addition, females treated with melatonin showed lower immobility time compared with males treated with melatonin $\left(\mathrm{t}_{(3.16)}=-4.74, \mathrm{p}=0.001<0.01\right)$.

In females, significant difference was revealed between the control group and the treated one $\left(\mathrm{t}_{(3.16)}=4.12\right.$, $\mathrm{p}=0.00001<0.001)$. Nevertheless, in males no significant difference was noted between groups $\left(\mathrm{t}_{(3.16)}=-0.89\right.$, 


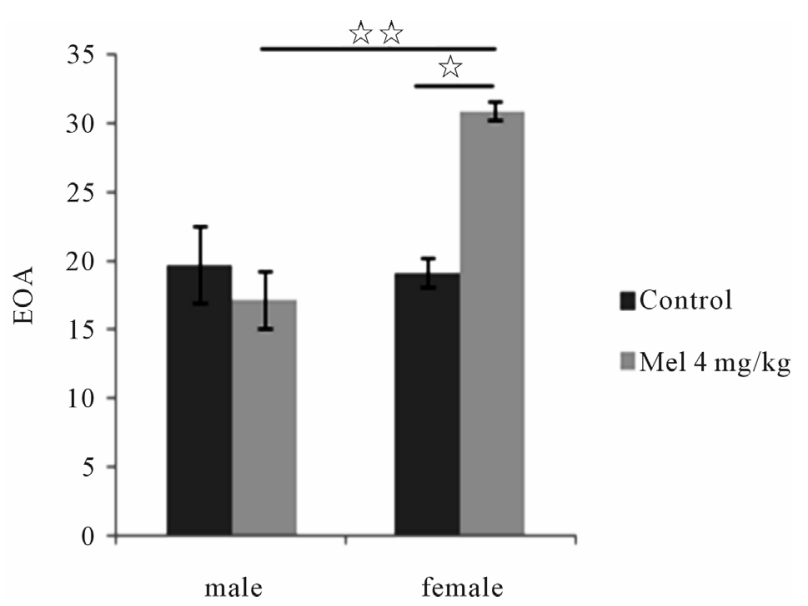

(a)

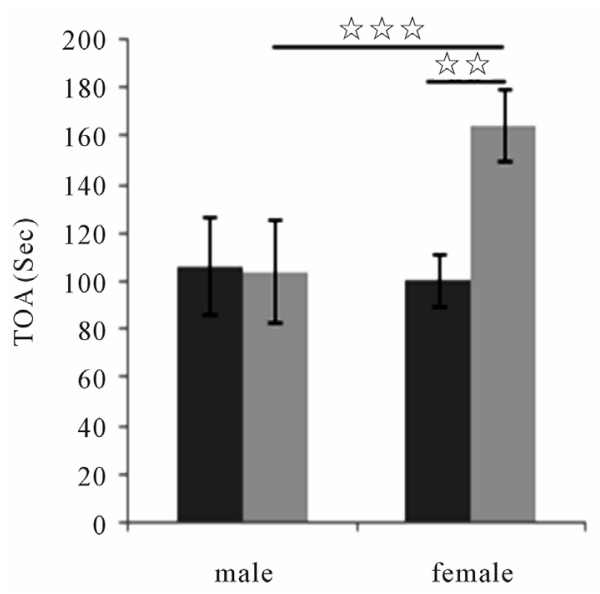

(b)

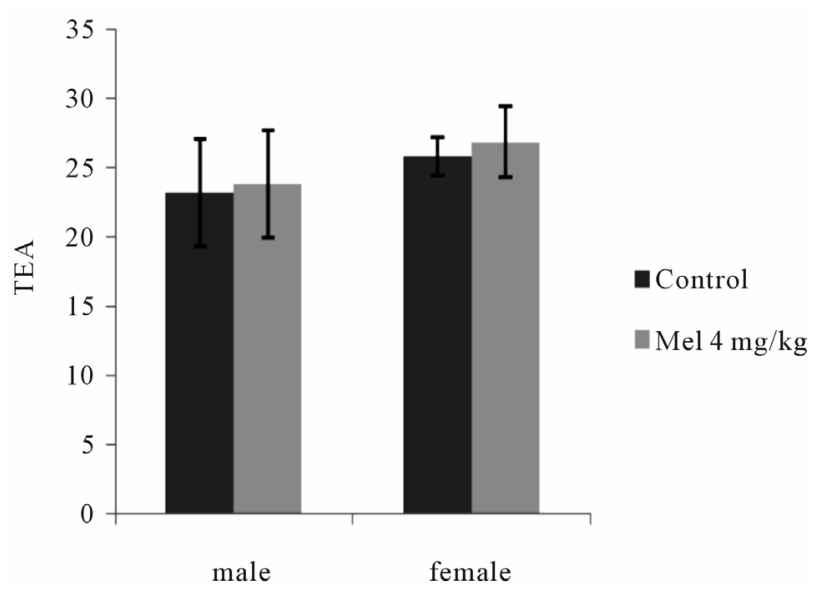

(c)

Figure 2. Mean (S.E.M.) (a) number of entries in the two exposed arms of elevated plus maze (EOA); (b) total amount of time spent exploring these arms (TOA) and (c) total number of arms entries (TEA) by female and male rats treated by $\mathrm{Mel}(4 \mathrm{mg} / \mathrm{kg})$ or $(\mathrm{NaCl} 0.9 \%)$ beginning at 8 weeks of age and during 8 weeks of treatment. Values at distal ends of horizontal bar differ, ${ }^{*} \mathrm{p}<0.05,{ }^{* *} \mathrm{p}<0.01,{ }^{* * *} \mathrm{p}$ $<0.001$.

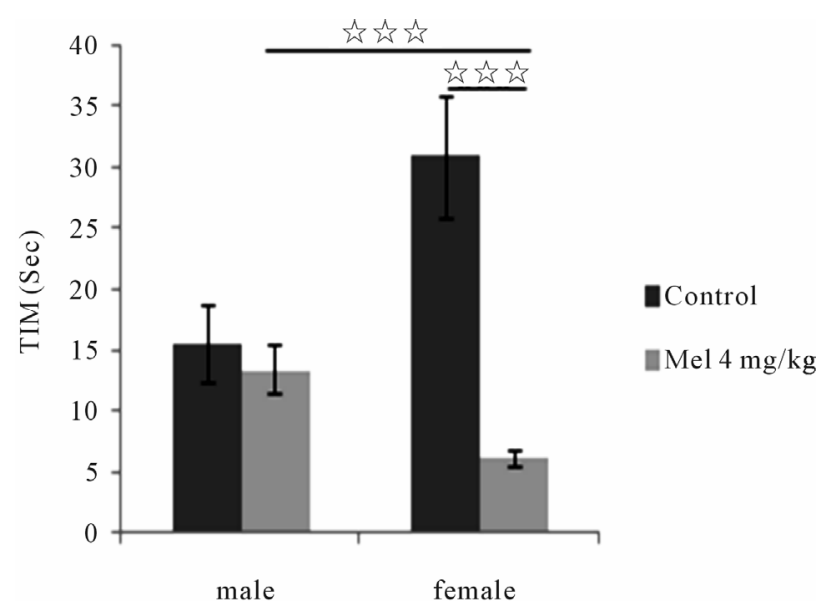

Figure 3. Mean (S.E.M.) Immobility time in Forced swimming test by female and male rats treated by $\mathrm{Mel}(4 \mathrm{mg} / \mathrm{kg})$ or $(\mathrm{NaCl} 0.9 \%)$ beginning at 8 weeks of age and during 8 weeks of treatment. Values at distal ends of horizontal bar differ, ${ }^{*}$ p $<0.05,{ }^{* *}$ p $<0.01,{ }^{* * *}$ p $<0.001$.

$\mathrm{p}=0.39>0.05)$

\subsection{Second Part: Effects of Melatonin on Ovariectomized Rats}

\subsubsection{Open Field Test}

\subsubsection{Time Spent in the Central Area (TCA) (Figure 4(a))}

Statistical analysis showed that sham operated rats treated with melatonin spent more time in the central squares compared to the ovariectomized rats treated with melatonin $(\mathrm{p}<0.05)$ and ovariectomized rats treated with $\mathrm{NaCl}(0.9 \%)(\mathrm{p}<0.001)$.

Moreover, a very significant difference was revealed between the sham operated group treated with melatonin and sham operated group treated with $\mathrm{NaCl}(0.9 \%)(\mathrm{p}<$ $0.01)$. However, no significant difference was found between the ovariectomized group treated with melatonin and those treated with $\mathrm{NaCl}(0.9 \%)(\mathrm{p}>0.05)$.

\subsubsection{Number of Returns to the Center (NRC) (Figure 4(b))}

The sham operated group treated with melatonin explored the central lines more than the sham operated treated group with $\mathrm{NaCl}(0.9 \%)(\mathrm{p}<0.05)$. The ovariectomized treated group with melatonin explored less the central tiles than the sham operated treated with melatonin $(\mathrm{p}<0.05)$. The frequency of returning to the center was significantly higher in sham operated treated group with melatonin than in ovariectomized treated group with $\mathrm{NaCl}(0.9 \%)(\mathrm{p}<0.01)$. However, no differences were noted between the group Ovx melatonin and $\mathrm{Ovx} \mathrm{NaCl}$ $(0.9 \%)(p>0.05)$. 


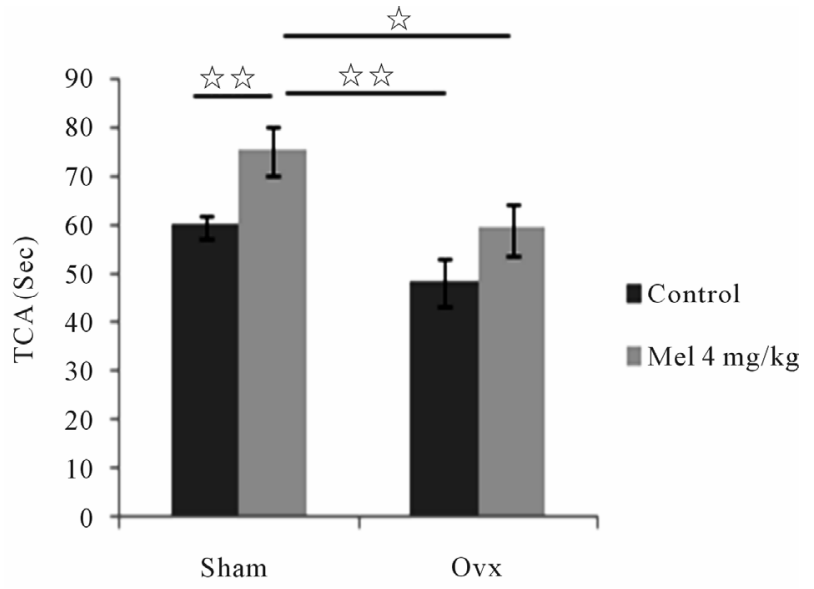

(a)

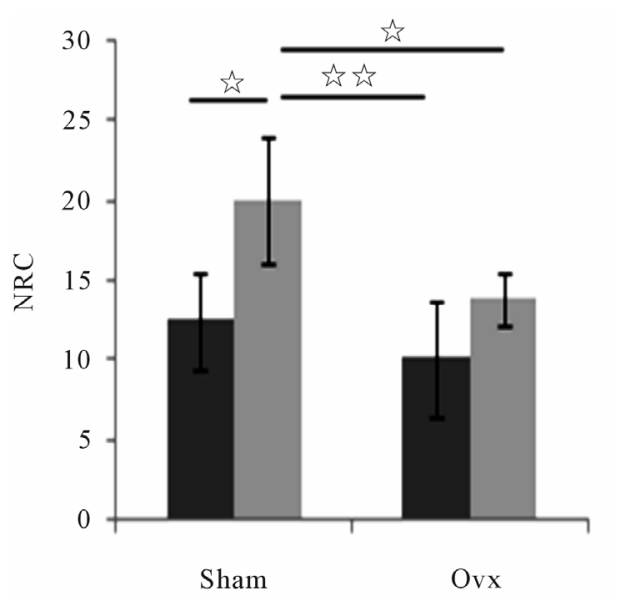

(b)

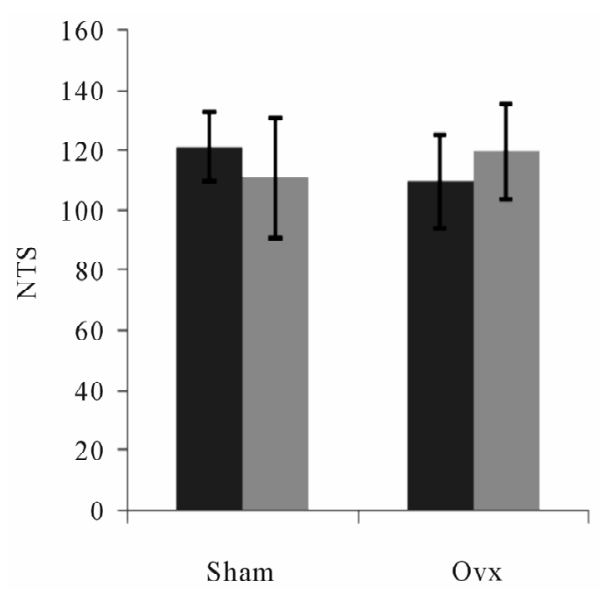

(c)

Figure 4. Mean (S.E.M.) (a) Total amount time spent in the center of the open field (TCA); (b) number of return into center area of the arena in the open-field behavior apparatus (NRC); and (c) the number of total squares (NTS); by ovariectomized and sham operated rats treated by Mel (4 $\mathrm{mg} / \mathrm{kg})$ or $(\mathrm{NaCl} 0.9 \%)$ beginning at 8 weeks of age and during 8 weeks of treatment. Values at distal ends of horizontal bar differ, ${ }^{*} \mathrm{p}<0.05,{ }^{* *} \mathrm{p}<0.01,{ }^{* * *} \mathrm{p}<0.001$.

\subsubsection{Locomotor Activity (NTS) (Figure 4(c))}

The locomotor activity was not altered by the ovariectomy or melatonin treatment $(\mathrm{p}>0.05)$.

\subsubsection{Elevated Plus Maze}

\subsubsection{Time Spent in Open Arms (TOA) (Figure 5(a))}

The effects of melatonin were more pronounced in Ovariectomized group than Sham operated group $(\mathrm{p}<0.01)$. As well, the Ovx group treated with $\mathrm{NaCl}(0.9 \%)$ spent less time in open arms compared to the sham operated group treated with melatonin $(\mathrm{p}<0.05)$. Similar results was observed between this latter group and the sham operated group treated with $\mathrm{NaCl}(0.9 \%)(\mathrm{p}<0.05)$.

\subsubsection{Entry to Open Arms (EOA) (Figure 5(b))}

The sham operated group treated with melatonin entered the open arms significantly more often than ovariectomized group treated with melatonin $(\mathrm{p}<0.001)$, and the sham operated group treated with $\mathrm{NaCl}(0.9 \%)(\mathrm{p}<$ $0.05)$. In addition, the Ovx group treated with $\mathrm{NaCl}$ $(0.9 \%)$ entered the EOA less often than the sham operated group treated with melatonin $(p<0.05)$, and this latter entered more often in EBO than the sham operated group treated with $\mathrm{NaCl}(0.9 \%)\left(\mathrm{t}_{(3.16)}=-3.68, \mathrm{p}=0.006\right.$ $<0.01)$.

\subsubsection{Total Entries in Arms (TEA) (Figure 5(c))}

The Locomotor activity was not altered by the ovariectomy or melatonin treatment $(\mathrm{p}>0.05)$.

\subsubsection{Forced Swimming Test}

Immobility time (TIM) (Figure 6)

The effects of melatonin wore more pronounced in the Ovx group compared to the sham operated group regarding the immobility time $(p<0.01)$. As well, the sham operated group treated with melatonin presented a TIM significantly lower than the sham treated with $\mathrm{NaCl}$ $(0.9 \%)(\mathrm{p}<0.05)$. However, no significant differences between groups Ovx $(\mathrm{Mel} / \mathrm{NaCl}(0.9 \%))$ were observed $(\mathrm{p}>0.05)$.

\subsection{Effects of Melatonin on Orchidectomized Rats}

\subsubsection{Open Field Test}

\subsubsection{Time Spent in the Central Area (TCA) (Figure 7(a))}

The orchidectomized (Orx) rats treated with melatonin spent more time in the central area than the sham operated rats treated with melatonin $\left(\mathrm{t}_{(3.16)}=-2.35, \mathrm{p}=0.04<\right.$ $0.05)$. However, there was no significant difference between the sham operated treated with melatonin and 


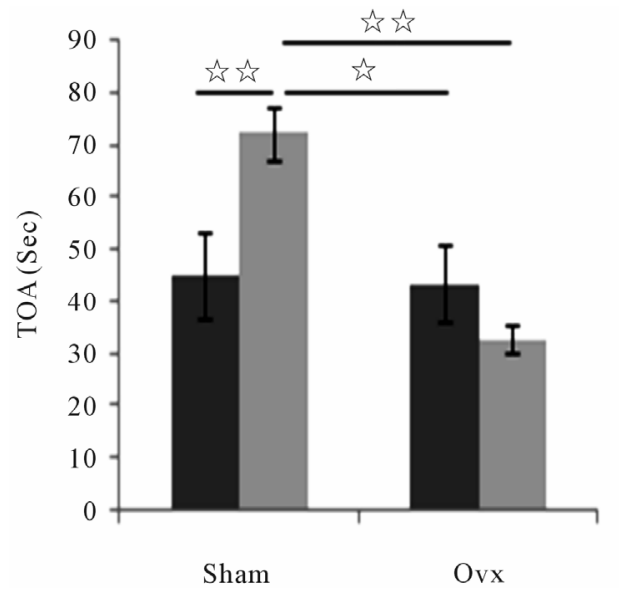

(a)

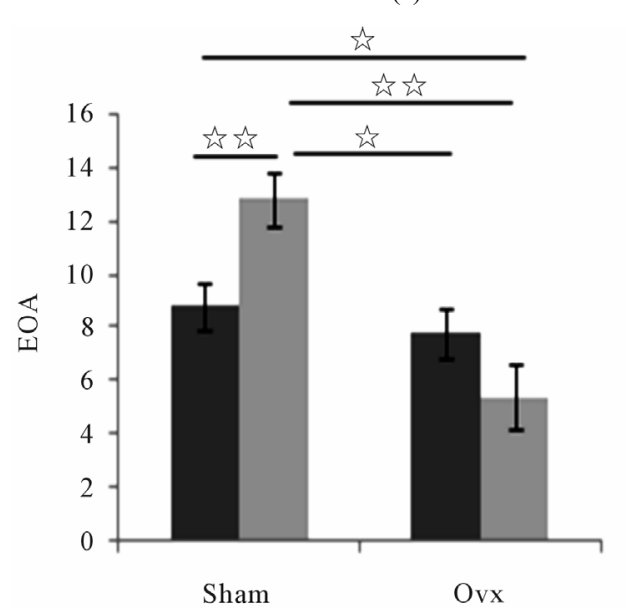

(b)

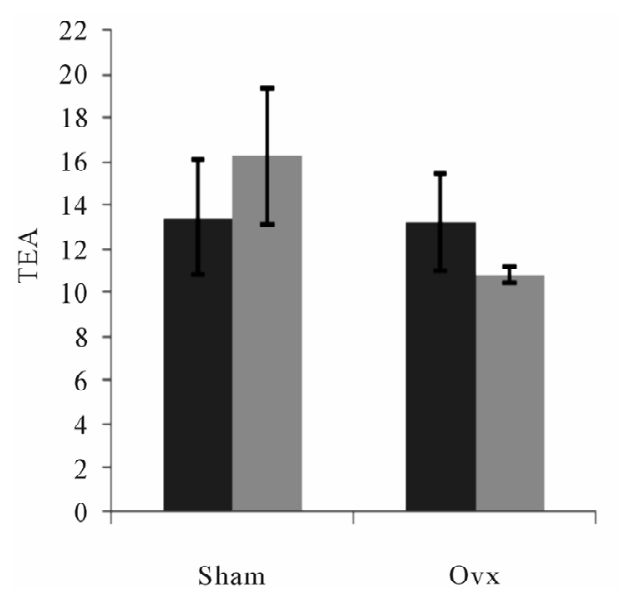

(c)

Figure 5. Mean (S.E.M.) (a) total amount of time spent exploring these arms (TOA); (b) number of entries in the two exposed arms of elevated plus maze (EOA) and (c) total number of arms entries (TEA) by ovariectomized and sham operated rats treated by $\mathrm{Mel}(4 \mathrm{mg} / \mathrm{kg})$ or $(\mathrm{NaCl} 0.9 \%)$ beginning at 8 weeks of age and during 8 weeks of treatment. Values at distal ends of horizontal bar differ, ${ }^{*} \mathrm{p}<0.05,{ }^{* *} \mathrm{p}<$ $0.01,{ }^{* * *} \mathrm{p}<0.001$.

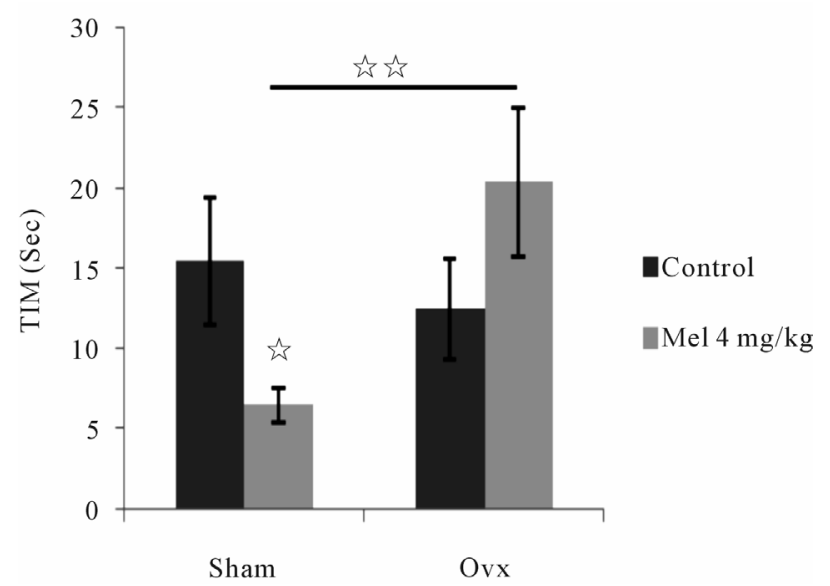

Figure 6. Mean (S.E.M.) Immobility time in Forced swimming test by ovariectomized and sham operated rats treated by Mel $(4 \mathrm{mg} / \mathrm{kg})$ or $(\mathrm{NaCl} 0.9 \%)$ beginning at 8 weeks of age and during 8 weeks of treatment. Values at distal ends of horizontal bar differ, ${ }^{*} \mathrm{p}<0.05,{ }^{* *} \mathrm{p}<0.01,{ }^{* * *} \mathrm{p}<0.001$.

sham operated treated with $\mathrm{NaCl}(0.9 \%)\left(\mathrm{t}_{(3.16)}=-0.11\right.$, $\mathrm{p}=0.09>0.05)$. Similarly, between the Orx melatonintreated and Orx treated with $\mathrm{NaCl}(0.9 \%)\left(\mathrm{t}_{(3.16)}=-1.99\right.$, $\mathrm{p}=0.08>0.05)$.

\subsubsection{Number of Returns to the Center (NRC) (Figure 7(b))}

Statistical analysis showed that Orx rats treated with melatonin explored significantly more the central squares than Orx rats treated with $\mathrm{NaCl}(0.9 \%)(\mathrm{p}<0.05)$, and sham operated rats treated with melatonin $(\mathrm{p}<0.01)$, the same compared to sham rats treated with $\mathrm{NaCl}(0.9 \%)$ (p $<0.01$ ). However, no significant difference between the sham group treated with melatonin and the group treated with sham $\mathrm{NaCl}(0.9 \%)$ was noted $(\mathrm{p}>0.05)$.

\subsubsection{Locomotor Activity (NTS) (Figure 7(c))}

The Locomotor activity was not altered by the orchidectomy or melatonin treatment $(\mathrm{p}>0.05)$.

\subsubsection{Elevated Plus Maze}

\subsubsection{Time Spent in Open Arms (TOA) (Figure 8(a))}

This parameter was significantly higher in orchidectomized rats treated with melatonin than sham operated group treated with melatonin $\left(\mathrm{t}_{(3.16)}=-2.75, \mathrm{p}=0.02<\right.$ $0.05)$, or with $\mathrm{NaCl}(0.9 \%)\left(\mathrm{t}_{(3.16)}=-2.34, \mathrm{p}=0.02<\right.$ 0.05). However, no significant difference between the sham group treated with melatonin and sham operated group treated with $\mathrm{NaCl}(0.9 \%)\left(\mathrm{t}_{(3.16)}=0.43, \mathrm{p}=0.67>\right.$ $0.05)$ were noted. Moreover, no significant difference was found between the Orx group treated with melatonin and the Orx group treated with $\mathrm{NaCl}(0.9 \%)\left(\mathrm{t}_{(3,16)}=\right.$ $-0.70, \mathrm{p}=0.26>0.05$ ). 


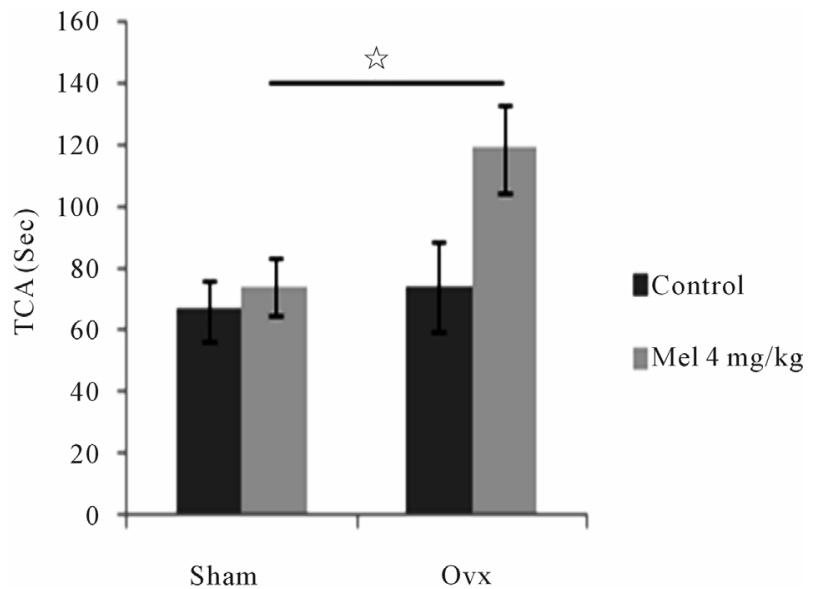

(a)

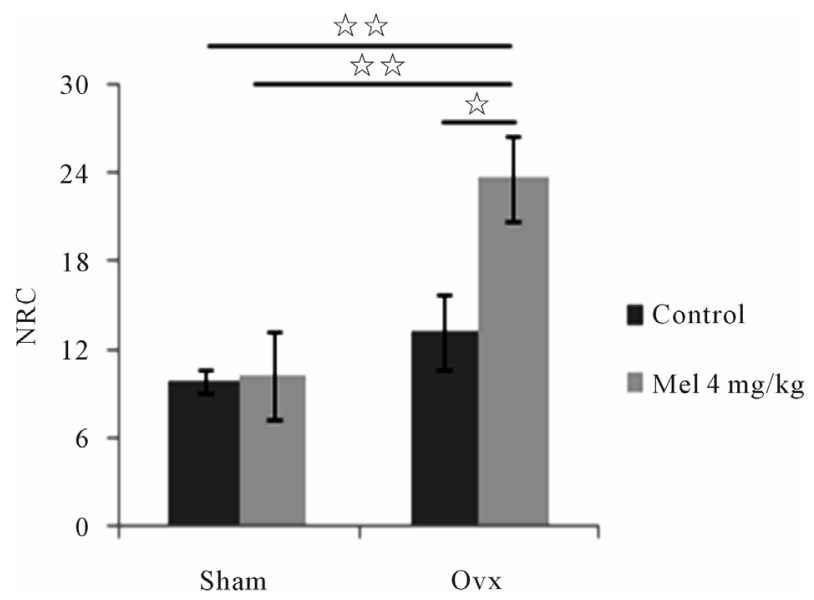

(b)

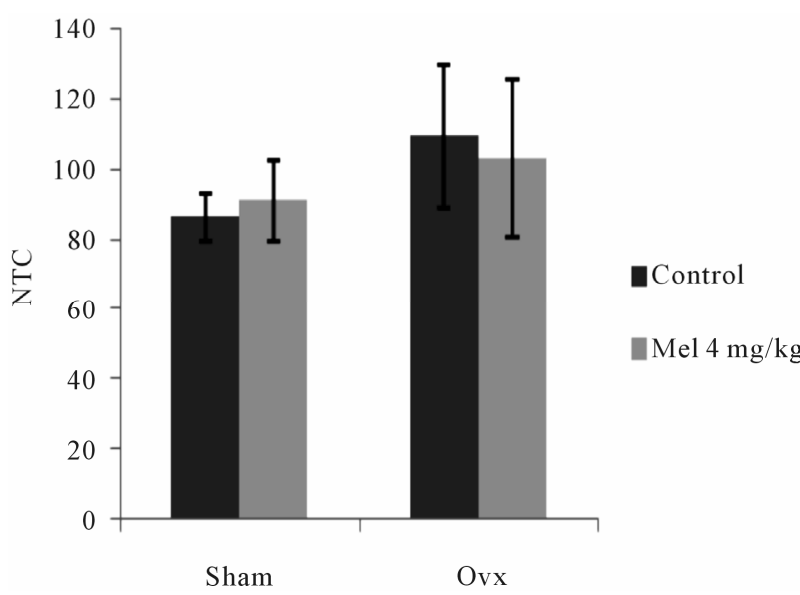

(c)

Figure 7. Mean (S.E.M.) (a) Total amount time spent in the center of the open field (TCA); (b) number of return into center area of the arena in the open-field behavior apparatus (NRC); and (c) the number of total squares (NTS); by orchidectomized and sham operated rats treated by Mel (4 $\mathrm{mg} / \mathrm{kg})$ or $(\mathrm{NaCl} 0.9 \%)$ beginning at 8 weeks of age and during 8 weeks of treatment. Values at distal ends of horizontal bar differ, ${ }^{*} \mathrm{p}<0.05,{ }^{* *} \mathrm{p}<0.01,{ }^{* * *} \mathrm{p}<0.001$.

\subsubsection{Entry to Open Arms (EOA) (Figure 8(b))}

Statistical analysis showed that Orx rats treated with melatonin had visited the open arms significantly more than Orx rats treated with $\mathrm{NaCl}(0.9 \%)(\mathrm{p}<0.05)$, and very significantly compared to sham operated treated rats by melatonin $(\mathrm{p}<0.01)$, the same result was observed compared to sham operated rats treated with $\mathrm{NaCl}(0.9 \%)(\mathrm{p}$ $<0.01)$. However, there was no significant difference between the sham operated group treated with melatonin and sham operated groups treated with $\mathrm{NaCl}(0.9 \%)(\mathrm{p}>$ $0.05)$.

\subsubsection{Total Entries in Arms (TEA) (Figure 8(c))}

No significant effect of orchidectomy and melatonin treatment was noted on locomotor activity $(p>0.05)$.

\subsubsection{Forced Swimming Test}

Immobility Time (Figure 9)

The immobility time in orchidectomized group treated with $\mathrm{NaCl}(0.9 \%)$ was lower than the sham operated group treated with $\mathrm{NaCl}(0.9 \%)(p<0.01)$. The same data was observed in Orx group treated with melatonin compared to the sham operated group treated with melatonin $(\mathrm{p}<0.01)$. This one presented a low immobility time compared to the sham group treated $\mathrm{NaCl}(0.9 \%)(\mathrm{p}$ $<0.001)$.

\section{Discussion}

The aim of this study was to analyze the influence of gonadectomy on antidepressant and anxiolytic effects of melatonin in male and female rats. In such studies of stress and emotional behavior, the behavioral variables that change in the presence of a typical stressful situation, is an essential tool in status and emotional activation level assessing of an individual. These variables should change in an emotional situation with intensities and high frequencies they would under normal non stress [33]. In our study, the assessment of these behaviors was based on behavioral tests (open field and elevated plus maze) to measure anxiety and (forced swimming test) to measure depressive levels. Overall, our results have shown an anxiolotic and antidepressant effects of exogenous Mel at $4 \mathrm{mg} / \mathrm{kg}$ in rats. Similar studies demonstrated that exogenous treatment with melatonin alone [34] or in conjunction with sub threshold doses of benzodiazepines [35] had an anxiolytic effect in several anxiety tests. Thereafter, in our study, these effects were sex dependent on three behavior tests: (OFT), chronic injection of Mel at 4 $\mathrm{mg} / \mathrm{kg}$ showed significant anxiolytic effect in both parameters TCA and NRC in female rats. Similar results were reported in females [36]. However, male rats are less active and don't show significant effects on both 


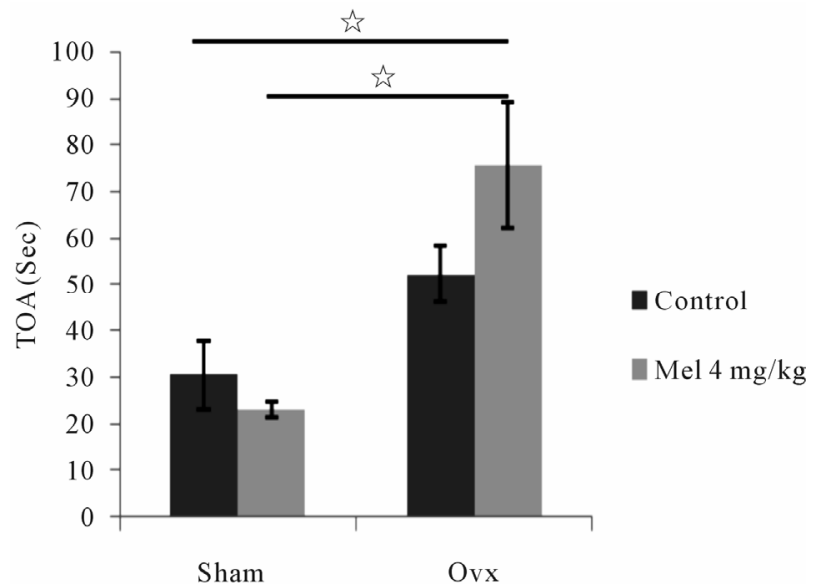

(a)

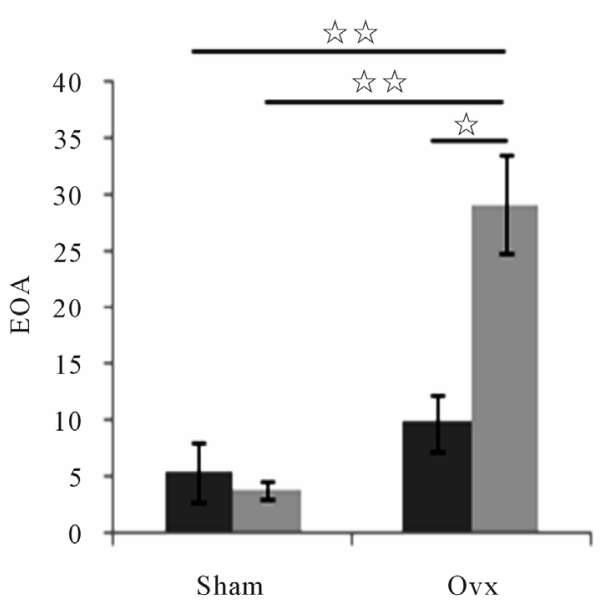

(b)

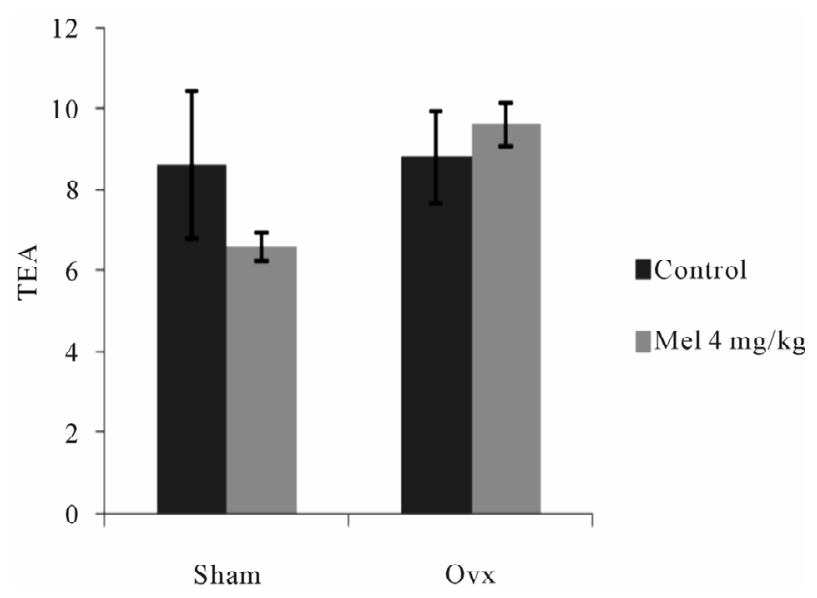

(c)

Figure 8. Mean (S.E.M.) (a) total amount of time spent exploring these arms (TOA); (b) number of entries in the two exposed arms of elevated plus maze (EOA) and (c) total number of arms entries (TEA) by orchidectomized and sham operated rats treated by $\mathrm{Mel}(4 \mathrm{mg} / \mathrm{kg})$ or $(\mathrm{NaCl} 0.9 \%)$ beginning at 8 weeks of age and during 8 weeks of treatment. Values at distal ends of horizontal bar differ, ${ }^{*} \mathrm{p}<$ $0.05,{ }^{* * *} \mathrm{p}<0.01,{ }^{* * * *} \mathrm{p}<0.001$.

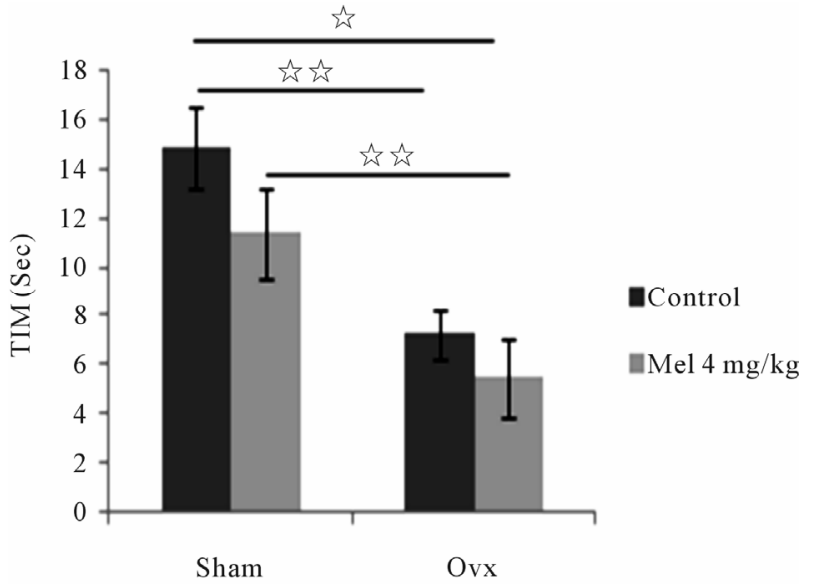

Figure 9. Mean (S.E.M.) Immobility time in Forced swimming test by orchidectomized and sham operated rats treated by Mel $(4 \mathrm{mg} / \mathrm{kg})$ or $(\mathrm{NaCl} 0.9 \%)$ beginning at 8 weeks of age and during 8 weeks of treatment. Values at distal ends of horizontal bar differ, ${ }^{*} \mathrm{p}<0.05,{ }^{* *} \mathrm{p}<0.01,{ }^{* * *} \mathrm{p}$ $<0.001$.

parameters, these results are consistent with other research aimed to study the effect of Mel injection in both sexes [24]. The same result was revealed on (EPM) test, chronic administration of $\mathrm{Mel}$ at $4 \mathrm{mg} / \mathrm{kg}$ showed significant effect on EOA and TOA parameters in females. However, male rats are less active and didn't show significant effects on the studied parameters, these results are consistent with those reported by [37].

Thus, in FST test, while it appears that acute melatonin administration at high dose $(30 \mathrm{mg} / \mathrm{kg})$ does not alter the immobility duration [38], lower doses $(10 \mathrm{mg} / \mathrm{kg})$ reduce immobility times [39]. In our results, chronic melatonin administration at $4 \mathrm{mg} / \mathrm{kg}$ decreased immobility behavior in females but not in males. The sex differences in FST test have previously reported [40]. In addition, intact male rats showed high immobility levels [15,41], and reduced antidepressants sensitivity $[15,16]$ compared to females.

The antidepressant effects of melatonin are likely mediated by the $5-\mathrm{HT}_{2 \mathrm{~A}}$ receptor, as biochemically [42] and behaviorally $[43,44]$ has been shown to act as a $5-\mathrm{HT}_{2 \mathrm{~A}}$ antagonist. Furthermore, decrease in the occurrence of immobility in the FST has been linked directly to reduction in activity at the $5-\mathrm{HT}_{2 \mathrm{~A}}$ receptor, and it has been suggested that antidepressant-like effects seen in the FST are ultimately regulated by the $5-\mathrm{HT}_{2 \mathrm{~A}}$ receptor [44].

However, it should be noted that the antidepressantlike action of melatonin could be mediated by melatonin receptor itself [45], or by interactions with other neurotransmitter systems, such as the GABAergic system [44, 46]. The difference between the sexes may be related to the hormones action on cognitive function and behavior 
in males as well as in females [47]. In the present study, the ovariectomy cancelled the antidepressant and anxiolytic effects of melatonin, furthermore, the progesterone and different estrogenic compounds produce antidepressant-like effects in ovariectomized rats [17-19,48]. Moreover, it has been reported that $\beta$-estradiol facilitate the antidepressant effect of DMI and FLX, through reduction in immobility and increase of climbing or swimming behaviors respectively [20]. But in males, the orchidectomy increases the antidepressant and anxiolytic effects of melatonin. However, systematic studies to evaluate the possible interaction between androgens and antidepressants have not been conducted [49]. Thus, our results confirm our hypothesis.

This sexual dimorphism is also observed in the psychiatric field. The psychotic disorders such as schizophrenia, showed a significant difference between men and women regarding the incidence and prevalence at onset age and therapeutic response quality. The organizational effects of sex hormones are usually observed before cerebral maturation, their differentiation is extended to puberty. Thus, Estrogens, allowed a rapid cerebral maturation in female than male. As evidence, in male brain development is characterized by progressive and regressive processes such as synaptic and axonal pruning and progressive myelination and lateralization of brain function more tardive than women [50]. This retardation justify that male brain has a greater vulnerability to pre- or perinatal accidents, involved in structural brain alterations. In schizophrenia, these structural alterations might explain the presence of negative symptoms or the early onset of the disease [51].

To summarize, further investigations are necessary to understand the mediation of sex hormones on melatonin actions.

\section{Acknowledgements}

This investigation was supported by PROTARS (D14/03, CNRST Morocco). Thanks are due to Dr. P. Pévet, from Institute of Cellular and Integrative Neurosciences, Department of Neurobiology of Rhythms, UPR-3212 CNRS, University of Strasbourg, France for the gift of melatonin and his skillful advice throughout the study. This work was also supported by GDRI Neurosciences (FranceMorocco) and Neuromed project. I wish also thank Dr. S. Boulbaroud and Dr. N. Benabid for their help.

\section{REFERENCES}

[1] H. Illnerova, J. Vaneek and K. Hoffmann, "Regulation of the Pineal Melatonin Concentration in the Rat (Rattus norvegicus) and the Djungarian Hamster (Phodopus sungorus)," Comparative Biochemistry and Physiology Part
A: Physiology, Vol. 74, No. 1, 1983, pp. 155-159. doi:10.1016/0300-9629(83)90727-2

[2] D. C. Klein and R. Y. Moore, "Pineal $N$-Acetyltransferase and Hydroxyindole-O-Methyltransferase: Control by the Suprachiasmatic Nucleus," Brain Research, Vol. 174, No. 2, 1979, pp. 245-262. doi:10.1016/0006-8993(79)90848-5

[3] R. Y. Moore, "Entrainment Pathways and the Functional Organization of the Circadian Timing System," In: R. M. Buijs, A. Kalsbeek, H. J. Romijn, C. M.-A. Pennartz and M. Mirmiram, Eds., Hypothalamic Integration of Circadian Rhythms, Elsevier, Amsterdam, 1996, pp. 101-117.

[4] R. Y. Moore, J. C. Speh and J. P. Card, "The Retinohypothalamic Tract Originates from a Distinct Subset of Retinal Ganglion Cells," Journal of Comparative Neurology, Vol. 352, No. 3, 1995, pp. 351-366. doi:10.1002/cne.903520304

[5] R. K. Leak, J. P. Card and R. Y. Moore, "Suprachiasmatic Pacemaker Organization Analyzed by Viral Transynaptic Transport," Brain Research, Vol. 819, No. 1-2, 1999, pp. 23-32. doi:10.1016/S0006-8993(98)01317-1

[6] W. J. Schwartz, N. Aronin, J. Takeuchi, M. R. Bennet and R. J. Peters, "Towards a Molecular Biology of the Suprachiasmatic Nucleus: Photic and Temporal Regulation of C-Fos Gene Expression," Seminars in Neuroscience, Vol. 7, No. 1, 1995, pp. 53-60. doi:10.1016/1044-5765(95)90017-9

[7] D. C. Klein, D. Sugden and J. L. Weller, "Postsynaptic Alpha-Adrenergic Receptors Potentiate the Beta-Adrenergic Stimulation of Pineal Serotonin N-Acetyltransferase," Proceedings of the National Academy of Sciences of USA, Vol. 80, No. 2, 1983, pp. 599-603.

doi:10.1073/pnas.80.2.599

[8] D. A. Golombek, M. Martini and D. P. Cardinali, "Melatonin as an Anxiolytic in Rats: Time Dependence and Interaction with the Central GABAergic System," European Journal of Pharmacology, Vol. 237, No. 2-3, 1993, pp. 231-236. doi:10.1016/0014-2999(93)90273-K

[9] J. Arendt, "Jet-Lag and Shift Work: (2). Therapeutic Use of Melatonin," Journal of the Royal Society of Medicine, Vol. 92, No. 8, 1999, pp. 402-405.

[10] R. G. Listen, "Ethologically-Based Animal Models of Anxiety Disorders," Pharmacology \& Therapeutics, Vol. 46, No. 3, 1990, pp. 321-340. doi:10.1016/0163-7258(90)90021-S

[11] P. Bracke, "Sex Differences in the Course of Depression: Evidence from a Longitudinal Study of a Representative Sample of the Belgian Population," Social Psychiatry and Psychiatric Epidemiology, Vol. 33, No. 9, 1998, pp. 420429. doi:10.1007/s001270050075

[12] I. O. Godfroid, "Sex Differences Relating to Psychiatric Treatment," Canadian Journal of Psychiatry, Vol. 44, No. 4, 1999, pp. 362-367.

[13] G. Fink, B. E. Sumner, R. Rosie, O. Grace and J. P. Quinn, "Estrogen Control of Central Neurotransmission: Effect on Mood, Mental State, and Memory," Cellular and Molecular Neurobiology, Vol. 16, No. 3, 1996, pp. 325-344. doi:10.1007/BF02088099 
[14] S. J. Alonso, M. A. Castellano, D. Afonso and M. Rodriguez, "Sex Differences in Behavioral Despair: Relationships between Behavioral Despair and Open Field Activity," Physiology \& Behavior, Vol. 49, No. 1, 1991, pp. 69-72. doi:10.1016/0031-9384(91)90232-D

[15] H. M. T. Barros and M. Ferigolo, "Ethopharmacology of Imipramine in the Forced Swimming Test: Gender Differences," Neuroscience \& Biobehavioral Reviews, Vol. 23, No. 2, 1998, pp. 279-286. doi:10.1016/S0149-7634(98)00029-3

[16] C. M. Contreras, H. Lara-Morales, M. Molina-Hernandez, M. Saavedra and G. Arrelli'n-Rosas, "An Early Lesion of the Lateral Septal Nuclei Produces Changes in the Forced Swimming Test Depending on Gender," Progress in Neuro-Psychopharmacology and Biological Psychiatry, Vol. 19, No. 8, 1995, pp. 1277-1284. doi:10.1016/0278-5846(95)00266-9

[17] L. Martınez-Mota, C. M. Contreras and M. Saavedra, "Progesterone Reduces Immobility in Rats Forced to Swim," Archives of Medical Research, Vol. 30, No. 4, 1999, pp. 286-289. doi:10.1016/S0188-0128(99)00024-X

[18] E. Estrada-Camarena, C. M. Contreras, M. Saavedra, I. Luna-Baltazar and C. Lopez-Rubalcava, "Participation of the Lateral Septal Nuclei (LSN) in the AntidepressantLike Actions of Progesterone in the Forced Swimming Test (FST)," Behavioural Brain Research, Vol. 134, No. 1-2, 2002, pp.175-183. doi:10.1016/S0166-4328(02)00023-2

[19] E. Estrada-Camarena, A. Fernandez-Guasti and C. LopezRubalcava, "Different Estrogenic Compounds Produce an Antidepressant-Like Effect in the Forced Swimming Test," Neuropsychopharmacology, Vol. 28, No. 5, 2003, pp. 830838. doi:10.1038/sj.npp.1300097

[20] I. L. Rachmann, J. R. Unnerstall, D. W. Pfaff and R. S. Cohen, "Estrogen Alters Behavior and Forebrain Cfos Expression in Ovariectomized Rats Subjected to the Forced Swimming Test," Proceedings of the National Academy of Sciences of USA, Vol. 95, No. 23, 1998, pp. 1394113946. doi:10.1073/pnas.95.23.13941

[21] P. C. Datta and M. G. King, "Melatonin: Effects on Brain and Behavior," Neuroscience \& Biobehavioral Reviews, Vol. 4, No. 4, 1980, pp. 451-458. doi:10.1016/0149-7634(80)90034-2

[22] A. S. Eison, R. P. Freeman, V. B. Guss, U. L. Mullins and R. N. Wright, "Melatonin Agonists Modulate 5-HT2A Receptor-Mediated Neurotransmission: Behavioral and Biochemical Studies in the Rat," Journal of Pharmacology and Experimental Therapeutics, Vol. 273, No. 1, 1995, pp. 304-308.

[23] U. Halbreich, "Hormonal Interventions with Psychopharmacological Potential: An Overview," Psychopharmacology Bulletin, Vol. 33, No. 2, 1997, pp. 281-286.

[24] A. L. Brotto, M. A. Barr and B. B. Gorzalka, "Sex Differences in Forced Swim and Open-Field Test Behaviours after Chronic Administration of Melatonin," European Journal of Pharmacology, Vol. 402, No. 1-2, 2000, pp. 87-93. doi:10.1016/S0014-2999(00)00491-X

[25] M. Durand, O. Berton, S. Aguere, L. Edno, I. Combourieu,
P. Mormede and F. Chaouloff, "Effects of Repeatedfluoxetine on Anxiety-Relatedbehaviours, Central Serotonergic Systems, and the Corticotropic Axis in SHR and WKY Rats," Neuropharmacology, Vol. 38, No. 15, 1999, pp. 893-907. doi:10.1016/S0028-3908(99)00009-X

[26] A. G. Nasselo, C. Machado, J. F. Bastos and L. Felicio, "Sudden Darkness Induces a High Activity-Lower Anxiety State in Male and Female Rats," Physiology \& Behavior, Vol. 63, No. 3, 1998, pp. 451-454. doi:10.1016/S0031-9384(97)00462-9

[27] L. Schramm, M. P. McDonald and L. E. Limbird, "The $\alpha_{2 \mathrm{~A}}$-Adrenergic Receptor Plays a Protective Role in Mouse Behavioral Models of Depression and Anxiety," Journal of Neuroscience, Vol. 21, No. 13, 2001, pp. 48754882 .

[28] L. Meyer, J. Caston and A. G. Mensah-Nyagan, "Seasonal variation of the Impact of a Stressful Procedure on open Field Behaviour and Blood Corticosterone in Laboratory Mice," Behavioural Brain Research, Vol. 167, No. 2, 2006, pp. 342-348. doi:10.1016/j.bbr.2005.09.023

[29] F. Clenet, E. Bouyon, M. Hasco and M. Bourin, "Light/ Dark Cycle Manipulation Influences Mice Behavior in the Elevated Plus Maze," Behavioural Brain Research, Vol. 166, No. 1, 2006, pp. 140-149. doi:10.1016/j.bbr.2005.07.018

[30] S. Pellower, P. Chopin, S. E. File and M. Briley, "Validation of Open: Closed Arms Entries in an Elevated PlusMaze as a Measure of Anxiety in the Rat," Journal of Neuroscience Methods, Vol. 14, No. 3, 1985, pp. 149-167. doi:10.1016/0165-0270(85)90031-7

[31] L. Torner, N. Toschi, A. Pohlinger, R. Landgraf and I. D. Neumann, "Anxiolytic and Anti-Stress Effects of Brain Prolactin: Improved Efficacy of Antisense Targeting of the Prolactin Receptor by Molecular Modeling," Journal of Neuroscience, Vol. 21, No. 9, 2001, pp. 3207-3214.

[32] R. D. Porsolt, G. Anton, N. Blavet and M. Jalfre, "Behavioural Despair in Rats: A New Model Sensitive to Antidepressant Treatments," European Journal of Pharmacology, Vol. 47, No. 4, 1978, pp. 379-391. doi:10.1016/0014-2999(78)90118-8

[33] A. Boissy, "Fear and Fearfulnss in Animals," Quarterly Review of Biology, Vol. 70, No. 2, 1995, pp. 165-191. doi: $10.1086 / 418981$

[34] C. Kopp, E. Vogel, M. C. Rettori, P. Delagrange, P. Renard, D. Lesieur and R. Misslin, "Regulation of Emotional Behaviour by Day Length in Mice: Implication of Melatonin," Behavioural Pharmacology, Vol. 10, No. 8, 1999, pp. 747-752.

[35] B. Guardiola-Lemaitre, A. Lenegre and R. D. Porsolt, "Combined Effects of Diazepam and Melatonin in Two Tests for Anxiolytic Activity in the Mouse," Pharmacology Biochemistry and Behavior, Vol. 41, No. 2, 1992, pp. 405-408. doi:10.1016/0091-3057(92)90118-Y

[36] F. P. Valle and B. B. Gorzalka, "Open-Field Sex Differences Prior to Puberty in Rats," Bulletin of the Psychonomic Society, Vol. 16, No. 6, 1980, pp. 429-431.

[37] M. S. Cohen, S. M. Kosslyn, H. C. Breiter, G. J. DiGi- 
rolamo, W. L. Thompson and A. K. Anderson, "Changes in Cortical Activity during Mental Rotation. A Mapping Study Using Functional MRI," Brain, Vol. 119, No. 1, 1996, pp. 89-100. doi:10.1093/brain/119.1.89

[38] M. L. Dubocovich, E. Mogilnicka and P. M. Areso, “Antidepressant-Like Activity of the Melatonin Receptor Antagonist, Luzindole (N-0774), in the Mouse Behavioral Despair Test," European Journal of Pharmacology, Vol. 182, No. 2, 1990, pp. 313-325. doi:10.1016/0014-2999(90)90290-M

[39] A. V. Shaji and S. K. Kulkarni, "Central Nervous System Depressant Activities of Melatonin in Rats and Mice," Indian Journal of Experimental Biology, Vol. 36, No. 3, 1998, pp. 257-263.

[40] W. P. Pare and E. Redei, "Sex Differences and Stress Response to WKY Rats," Physiology \& Behavior, Vol. 54, No. 6, 1993, pp. 1179-1185. doi:10.1016/0031-9384(93)90345-G

[41] S. J. Alonso, M. A. Castellano, D. Afonso and M. Rodriguez, "Sex Differences in Behavioral Despair: Relationships between Behavioral Despair and Open Field Activity," Physiology \& Behavior, Vol. 49, No. 1, 1991. pp. 69-72. doi:10.1016/0031-9384(91)90232-D

[42] A. S. Eison, R. P. Freeman, V. P. Gus, U. L. Mullins and R. N. Wright, "Melatonin Agonists Modulate 5-HT2A Receptor Mediated Neurotransmission: Behavioural and Biochemical Studies in the Rat," Journal of Pharmacology and Experimental Therapeutics, Vol. 273, No. 1, 1995, pp. 304-308.

[43] B. B. Gorzalka, L. A. Brotto and J. J. Hong, "Corticosterone Regulation of 5-HT2A Receptor Mediated Behaviors: Attenuation by Melatonin," Physiology \& Behavior, Vol. 67, No. 3, 1999, pp. 439-443. doi:10.1016/S0031-9384(99)00096-7

[44] V. Raghavendra and S. K. Kulkarni, "Melatonin Reversal of DOI-Induced Hypophagia in Rats: Possible Mechanism by Suppressing 5-HT(2A) Receptor-Mediated Acti- vation of the HPA Axis," Brain Research, Vol. 860, No. 1-2, 2000, pp. 112-118. doi:10.1016/S0006-8993(00)02031-X

[45] E. Sibelle, Z. Sarnyai, D. Benjamin, J. Gal, H. Baker and M. Toth, "Antisense Inhibition of 5-Hydroxytryptamine 2A Receptor Induces an Antidepressant-Like Effect in Mice," Molecular Pharmacology, Vol. 52, No. 6, 1997, pp. 1056-1063.

[46] D. H. Overstreet, O. Pucilowerski, M. Retton, P. Delagrange and B. Guardiola-Lemaitre, "Effect of Melatonin Receptor Ligands on Swim Test Immobility," Neuroreport, Vol. 9, No. 2, 1998, pp. 243-253. doi:10.1097/00001756-199801260-00014

[47] D. A. Golombek, P. Pevet and D. P. Cardinali, "Melatonin Effects on Behavior: Possible Mediation by the Central GABAergic System," Neuroscience \& Biobehavioral Reviews, Vol. 20, No. 3, 1996, pp. 403-412. doi:10.1016/0149-7634(95)00052-6

[48] P. Palanza, "Animal Models of Anxiety and Depression: How Are Females Different," Neuroscience \& Biobehavioral Reviews, Vol. 25, No. 3, 2001, pp. 219-233.

[49] E. Estrada-Camarena, A. Fernandez-Guasti and C. LopezRubalcava, "Interaction between Estrogen Compounds and the Antidepressants Desipramine or Fluoxetine in Forced Swimming Test (FST)," Psychopharmacology, Vol. 173, No. 1-2, 2004, pp. 144-145. doi:10.1007/s00213-003-1707-4

[50] L. Martınez-Motaa and A. Fernandez-Guasti, "Testosterone-Dependent Antidepressant-Like Effect of Noradrenergic But Not of Serotonergic Drugs," Pharmacology, Biochemistry and Behavior, Vol. 78, No. 4, 2004, pp. 711718. doi:10.1016/j.pbb.2004.05.016

[51] P. E. Cowell, D. J. Kostianovsky, R. C. Gur, B I. Turetsky and R. E. Gur, "Sex Differences in Neuroanatomical and Clinical Correlations in Schizophrenia," American Journal of Psychiatry, Vol. 153, No. 6, 1996, pp. 799805. 